\title{
COMMODIFICATION OF CULTURAL IDENTITIES AND/OR EMPOWERMENT OF LOCAL COMMUNITIES: DEVELOPING A ROUTE OF NUCLEAR TOURISM
}

\author{
Natalija Mažeikienè \\ Vytautas Magnus University, Lithuania \\ Eglè Gerulaitienè \\ Vytautas Magnus University, Lithuania \\ Šiauliai University, Lithuania
}

\begin{abstract}
Research presented in the paper focuses on commodification of cultural identities and community empowerment strategies of cultural tourism in Visaginas. One of challenges in developing tourism is orientation toward profit and commodification of culture, which becomes a problem in regard to practicing authentic identities. The article presents efforts of researchers working in the project EDUATOM to scientifically substantiate construction of new educational nuclear/ atomic tourism route in the Ignalina Nuclear Power Plant (INPP) region. The authors discuss what diverse parameters and elements of place identity could be included and represented in the tourism in Visaginas and how community empowerment and involvement of different stakeholders might contribute to practicing various commodification strategies. The article analyses commodification of cultural identities and community empowerment strategies of educational, cultural, nuclear/atomic tourism in Visaginas, using research strategy of case study, including methods of document analysis, conversations (formal and informal) with stakeholders, secondary data analysis, construction of Post-Soviet identities and empowerment of local communities.
\end{abstract}

Keywords: cultural identities, commodification of cultural identities, self-commodification, cultural tourism, Visaginas, Ignalina Nuclear Power Plant, nuclear tourism, atomic tourism, empowerment.

\section{Introduction}

The article presents efforts of researchers working in the project EDUATOM $^{1}$ to scientifically substantiate construction of new educational nuclear tourism route in the Ignalina Nuclear Power Plant (hereafter, INPP) region in Lithuania by applying new approaches in STEM education and seeking to

\footnotetext{
${ }^{1}$ The project 'The Didactical Technology for the Development of Nuclear Educational Tourism in the Ignalina Nuclear Power Plant (INPP) Region (EDUATOM)' (No. 01.2.2-LMT-K-718-01-0084/232) is funded by the grant from the Research Council of Lithuania.
}

(C) Rēzeknes Tehnologiju akadèmija, 2018 http://dx.doi.org/10.17770/sie2018vol1.3381 
empower local communities of town Visaginas which was created and built as a satellite-settlement for the workers of the INPP. It is envisaged by the researchers, social partners and stakeholders participating in this initiative that the new route will be consistent with the idea and practice of similar nuclear/ atomic tourism museums, expositions and sites existing in other countries. Atomic tourism route under construction will embrace an exposition of Information Centre at INPP which will be adjusted to the new conception of so called 'Movement of Science Centres' (Beetlestone, 1998), when science communication expositions (science centres, science museums, and etc.) include elements of edutainment (entertainment + education). Referring to the new concept of Science Centre the exposition at the INPP will be based on interactivity, application of IT technologies, and will rely on visitor's sensory experience and educational needs of different groups of visitors. The future exposition will stick to the idea of science museums and tourist centres to combine the exposition with other activities, i.e. lectures, creative laboratories, camps, events, performances, traveling, temporary exhibitions. Current explosion of Information Centre at the INPP is dedicated mostly to technological and security aspects of decommissioning. The first block of the INPP was suspended in 2004, the second in 2009. Decision on decommissioning was made upon Lithuania's accession to the EU. The completion of the INPP decommissioning works is planned for the year 2038. It is worth mentioning that the current exposition presents the historical and social development of identity of the town of Visaginas quite poorly and fragmentarily.

Apart the Information Centre at the INPP, the future nuclear tourism route will include other objects and sites in Visaginas town. In this way science communication on atomic energy will be complemented by elements of cultural tourism by exposing multicultural and multilingual identity of local community, specific and unique demographic profile of Visaginas and identity of the town. The town was built in 1975 and before 1992 it had the name „Sniečkus“ which was a surname of leader of the Lithuanian Communist Part. The future workers, most of whom were of Russian origin, arrived (were sent by Soviet authorities) from various places in the Soviet Union to build the town. Today most of the inhabitants of the town are Russian-speaking inhabitants (e.g., there are $15 \%$ of Lithuanians and Belarusians equally). Initially designed by Soviet authorities as a satellite-settlement for the workers of the plant, Visaginas is still isolated from the rest of the country both culturally and geographically. According to Baločkaitè (2010), Visaginas represents a complex and specific development of post-soviet identity in a mono industrial urban site ('a migrant island'), which is very difficult to position in the post-Soviet cultural, political and economic context. From cultural and heritage tourism perspective, Visaginas becomes a site of Soviet 
industrial and urban heritage, 'a showcase of socialism' (Freimane, 2014) and in this way turns into dissonant and contested heritage. All the above mentioned aspects suggest a specific collaborative and empowering approach for the development of nuclear tourism route while involving local and national stakeholders, negotiating and mediating ways and strategies of local identity building within the framework of more democratic politics of identity and memory.

The aim of the paper is to analyze commodification of cultural identities and conceptualize community empowerment strategies of educational, cultural, nuclear tourism in Visaginas. The article focuses on the following objectives:

1) Disclose the concept of commodification in representing cultural identities;

2) Identify dissonant strategies of Post-Soviet identities, discuss strategies and practices of Post-Soviet urban identities in tourism and envisage nuclear tourism conditions in the development of this type of tourism in Visaginas;

3) Reveal community empowerment strategies and the role of stakeholders in developing nuclear tourism in Visaginas.

The article analyses commodification of cultural identities and community empowerment strategies of educational, cultural, nuclear/atomic tourism in Visaginas, using research strategy of case study, including methods of document analysis, conversations (formal and informal) with stakeholders, secondary data analysis, scientific literature review, analyzing concepts of commodification, construction of Post-Soviet identities and empowerment of local communities.

\section{Commodification of identities as commercialised hospitality in cultural tourism}

One of the challenge in developing tourism is orientation toward profit and commodification of culture which becomes a problem in regard to practicing authentic identities. Scholars stress ambiguity of "sharing culture" in tourism industry when culture and identity, traditions and cultural practices are 'sold out', transformed into tourism products, and representations, commodity and alienable products for consumption and for the benefit of tourists (Bunten, 2008; Cassel \& Maureira, 2017). In this case a distinction between the acted identity and the 'real' identity not presented to tourists could occur (Stronza, 2008). It is discussed by scholars whether such creation of tourist product and commodification lead to a loss of cultural authenticity or it could help to reinforce cultural identity and strengthen the culture (Bunten, 2008; Cassel \& Maureira, 2017). 
Cultural tourism is defined here not just as "monumental tourism" which is aimed on visiting monuments and cultural sites (museums, monuments, archaeological and historical sites). We rely on the broader notion of cultural tourism which is mentioned by N. Gal1-Espelt (2012) and refers to the definition provided by International Council of Monuments and Sites (ICOMOS): 'Cultural tourism may be defined as any activity that allows visitors the experience of discovering other people's ways of life, allowing them to experience on the one hand their customs, traditions, physical environment or ideas, and on the other, access to places of architectural, historical, archaeological or any other type of cultural value' (Ibid., p. 47).

Representatives of culture as cultural tourism workers in order to sell a tourist product perform a self-commodification which 'can be broadly defined as a set of beliefs and practices in which an individual chooses to construct a marketable identity product while striving to avoid alienating him- or herself' (Bunten, 2008: 381). The self-commodification is conceptualised as a complicated psychological and intercultural communication process which deals with convergence of emotional labour, identity construction, and the politics of representation. Creation of representations of local culture usually is performed in line and within the framework of hegemonic politics of representations: it is based on perceptions and concepts shared by dominant society and cultural majority and attached to the local culture.

Certain strategies and forms how this self-commodification is carried out are recognised and distinguished. It is carried out by presenting concrete culture and identity in uniform, standardized and simplified way and by self-exoticizing as the Other and by meeting tourists' desires tourist to have an encounter with the Other. For instance, A. C. Bunten (2008) presents a case of tribal tours in Alaska when local cultural tourist workers (Native Alaskans) presents identity of their culture in the frame how White majority perceive indigenous people. Some authors note that such encounter with the Other is unequal whereas the Western, middle-class guests see representatives of local cultures as places the different and exotic (Cassel \& Maureira, 2017). The condition of being an exotic Other in cultural tourism in order to make profit and sell out the culture and identity as commodity may contradict to identities and authentic practices which are exercised by local people. There could be ,tensions within these expressions of the local and what (and how) community memories are validated and legitimised and what are marginalised or erased altogether '(Murtagh et al., 2017: 508).

Another possible self-commodification strategy while presenting own culture and identity in cultural tourism industry as a product and service, besides the self-exoticization, is to put up resistance by presenting diverse forms of displays and expressions of identity and trying to strive against stereotyping 
(Bunten, 2008). In quite complicated process of balancing between contradictory and contesting strategies and practices local tourist workers perform a role of "cultural brokers" by negotiating between expressions of identity of hosts (representatives of local culture) and expectations and stereotypes of dominant cultural group (guests). This cultural brokering could induce an exchange of expectations and expressions of identities in both groups (hosts and guests) and diminish tensions caused by unequal configuration of power within concrete politics of identity.

In the process of developing the nuclear tourist route in Visaginas and the INPP region the scholars and local stakeholders recognise inevitability of (self-) commodification which becomes a constituent element of tourism in its orientation towards generation of revenue. Additionally, other aims of the tourism in this region are identified. The tourism could be a vehicle to empower local communities and foster a new sense of belonging.

\section{Envisaging self-commodification strategies in nuclear and postsocialist heritage tourisms in Visaginas}

When designing the tourist route in the INPP region, we take into consideration the nature of self-commodification discussed above. One of the possible ways in cultural tourism is to present identity through self-exoticizing as the Other. Seeking to attract tourists and create motivation to travel several hundred kilometres from their home towns and come to remoted place (Visaginas), some distinctive and unique ('exotic') attraction should be offered. On the one hand, exotic otherness and specificity could be constructed by appealing to representation and image of the atomic city and the INPP, which used to play a significant role in national economy by producing electricity in a specific way - by deploying a nuclear energy for power which is different from other types of energy resources (oil, hydroelectric power, wind power plants). Improving the exposition at the INPP by adjusting it to the idea of the Science Centre and presenting knowledge about nuclear energy in a mode of edutainment could become such an self-exoticization element which could attract the tourists. One more attractive element here could be a reference to the place of nuclear energy in world economy. Exposition at the INPP could be presented as one of similar objects of nuclear/ atomic museums, sites and objects in the world. In this case the exposition will include not only narrative on security and safety of decommissioning. It could embrace broader issues of nuclear physics. Additionally, the exposition could encompass social, cultural and symbolic representations exposing discourses of mono-industrial atomic cities and social consequences, environmental concerns, post-industrial and post-apocalyptic 
images, associations and references to other nuclear energy objects (Chernobyl, Hiroshima, Fukushima, etc). In this case certain elements of 'dark tourism' may appear.

Another unique quality of this region, which could be used in the selfexoticization strategy, is specific and distinctive post-soviet identity of Visaginas which was built in the Soviet era and is directly associated with the first 'exotic' feature - atomic energy industry and the INPP. Although Lithuania together with all neighbouring countries belongs to the post-Soviet region, the situation of Visaginas is unique. The question here arises whether and under what circumstances, the Soviet identity of the Visaginas city can become a tourist product and commodity. Under what conditions Lithuanian tourists would "buy" this Soviet and post-Soviet specificity of the city and consider it as different from what they see in their own towns and home places. At the same time, whether the community of Visaginas is ready to "sell" this commercial product.

Considering the possibility to transform identity of the town into a commercial tourist product and commodity one more aspect that should be taken into consideration is that identity is not stable, static and immutable. Culture is changing and evolving, it is a dynamic concept that varies in time and space. In cultural tourism it should be decided what diverse parameters and elements of place identity will be included and represented in the tourism. Change of place identity in Visaginas could be associated with several stages of life of the town. I. Freimane (2014) distinguishes three main stages, according to the major political transformations in the country. The first stage begins with the decision to build the INPP and Visaginas in 1974. The first stage is associated with the Soviet period when the city was built by referring to the highest standards of quality of life at that time in Soviet Union and seeking to construct the most powerful nuclear power in the world. The beginning of the second stage of development of the town is associated with new status of the INPP when in 1991 the INPP becomes an important strategical industrial object which generates energy for independent Lithuania. The third stage of the development of the town is associated with entering EU in 2004 when decommissioning of the INPP becomes a condition and prerequisite for Lithuania to become EU member. All these 3 historical stages implied transformations and redefinition of identity moving from enthusiasm, proud of living in 'soviet paradise' and feeling of privilege in Soviet times to uncertainty, fear and hope in the period of negotiations with EU during the second stage; nostalgia, narratives of decline and anxiety about the future in the third stage after closure of two blocks of the INPP.

Apart from the historical transformations of the city's identity, it should be noted that due to its Soviet identity Visaginas falls into category of dissonant and contested heritage. Variety of ways of dealing with this type of heritage and 
'unwanted' past in Visaginas has been described by R. Baločkaite (2010). The author refers to postsocialist urban identities formation strategies distinguished by C. Young and S. Kaczmarek (2008) whereas 'unwelcome past' is overcome by applying decommunization, returning to the pre socialist Golden Age, and fostering Westernization/Europeanization. These strategies are specific case of formation of place identity with enacting processes of historical memory, remembrance and forgetting. According to Baločkaitè $(2010,2012)$ identity formation in Visaginas as one of the planned socialist cities has poor reference to pre-socialist past, so the strategy of looking for the Golden Age outside of the Soviet era cannot be realized in the region. That is why other strategies are being used more actively. Anyway, as stated Baločkaité, all these other strategies are quite ideologically ambivalent. One can find a strategy of the use of deideologized images of young and green city with beautiful nature. The third strategy of construction post-soviet urban identity is partial decommunization and private nostalgia for the socialist past and public denial in official institutionalised discourses. 'In Visaginas, the old identities have not been deconstructed and the unwanted past remains present in multiple forms, including - inherited nostalgia of the first post-socialist generation (the restaurant 'Third Block'). The Soviet past is suppressed and suspended but not cancelled; it is rendered invisible in official representations but memorialized in daily life' (Baločkaitè, 2010: p. 51). One more strategy of construction of post-socialist identity distinguished by the author is commercialisation of the soviet past ('Socialism for Sale') in socialist heritage tourism as a specific niche within heritage tourism which has been successfully realised in Poland and other post-communist countries (i.e. 'Grūtas Park' in Lithuania) by positioning certain places (i.e. Nowa Huta - district of Krakow) as a socialist landmark and relating to authentic experience of socialism. It is worth noting that variety of representation strategies is deployed here including grotesque, postmodern pastiche with nostalgia, irony and parody. All the strategies of constructing of place identity in Visaginas as a post-socialist town will be taken into consideration while developing atomic/ nuclear route and arranging discussions with stakeholders.

\section{Community empowerment and role of stakeholders in developing nuclear tourist route in Visaginas}

Community empowerment is deemed to encourage communities to participate in tourism planning and development. Some authors (Nyaupane et al., 2006) suggest that members of the host community should be involved in tourism planning because they: (a) have an historical understanding of how the region adapts to change; (b) will be the ones most closely affected by tourism; and (c) will be expected to become integral part of the tourism product. As it is noted in 
the literature, participation can be facilitated through surveys, focus groups and charters, which can set down the rights of the community (Tukamushaba \& Okech, 2011). This promotes collaboration, transparency and accountability for all destination stakeholders. When we discuss the case of Visaginas community, the stakeholders, who should be involved in the building consensus about tourism related policies are: Visaginas Municipality (Strategic planning department, Education, culture and sport department); INPP; NGOs; municipal-owned cultural, recreation and sports institutions; INPP Region Business and Tourism Information Centre; school communities; politicians (city council, political parties, mayor); artists (including artists from other cities); entrepreneurs; and scholars. Involvement of the local community creates a bond through mutual understanding and trust. It thus helps to reduce potential conflicts and all the costs associated with their resolution (Bramwell \& Sharman, 1999). Jackson (2006) developed a framework to foster the process of community participation and involvement in tourism development. He showed that the process begins with identification of key stakeholders and interest groups, establishment of communication mechanisms and information flow channels among stakeholders (Tukamushaba \& Okech, 2011). As the key stakeholders who would contribute to the development of Visaginas cultural tourism were identified, it is crucial to analyse different interests that these stakeholders possess in the framework of tourism development.

Visaginas Municipality and other public authorities. Economic and social development of Visaginas municipality for many years has been closely related to the operation of the INPP, and the current urban development vision is linked both to the innovative development of the industry in Visaginas and promotion of Visaginas as the centre of energy competency. Representatives of the public authorities stress the role of nature and culture in the INPP region which provides opportunities for educational and cultural tourism. The main tourist attractions in the region are named such as sports and sport leisure activities (walking, cycling, boating, kayaking and etc.) and countryside accommodation, multicultural cuisine of the region. However, it is stressed in conversations with representatives of public authorities that other towns and places of the region (Ignalina and Zarasai) have richer and more attractive nature resources and facilities.

Speaking about quality of cultural and leisure facilities and activities in the town it could be noted that Visaginas municipality has carried out a survey of inhabitants. A considerable amount of respondents (44.31\%) is not satisfied with the city's cultural life. Similar number of respondents (40\%) negatively evaluates the infrastructure of cultural institutions and cultural needs. Also, respondents indicated that there is a lack of water entertaining, tourism routes, tourism and educational settings. The research showed that Visaginas inhabitants rated the 
worst tourism information and services. Analysing Visaginas municipality strategic development plan 2016-2022 it was found that the municipality seeks to create attractive and effective use of existing leisure and sports facilities. But it is still notable that municipality focuses on nature more than on the cultural needs of inhabitants and tourists. This attitude indicates a greater focus on tourism which is based on resources of local nature than on cultural assets. Referring to strategies of place identity construction mentioned above in the article we can admit that authorities emphasize de-ideologized image of Visaginas as young and green town with comfortable conditions to live and spend leisure time. Multicultural, multilingual and multi-ethnic profile of Visaginas is perceived as an important resource to represent uniqueness of the town and deliver 'commercialised hospitality' in cultural and recreational tourism. Strategy of positioning of the town as socialist city within the framework of socialist heritage tourism has not been sounded and was evaluated by representative of public authorities quite negatively in brainstorming discussions. It confirms once more the observation made by R. Baločkaite (2010) that the official and institutional discourse tries to minimize the socialist past while constructing place identity.

Ignalina Nuclear Power Plant is the state enterprise. As one of the main stakeholders the INPP supports idea of nuclear tourism in the region. Still the interest in tourism development is specific, as its main task is to carry out the decommissioning of the INPP, which is set to be completed by 2038. The enterprise's goal is to become an expert on safe and efficient nuclear facility decommissioning. Current role of the INPP in tourism development is to spread information about safety and security in the use of nuclear power. The INPP has intention to modernise and promote activities of Information Centre which is very active in arranging tours for domestic and foreign tourists. Up to now the INPP has been visited by about 95,000 visitors, 5517 tours have been organized. On the other hand, the INPP is a stakeholder which might contribute to the development of soviet heritage tourism. Site of the INPP (reactors, other industrial infrastructure) as well as some facilities (for instance, soviet style canteen) could be used while developing soviet industrial and urban heritage tour. As it was discussed by Baločkaite $(2010,2012)$, socialist past is „exotic“ and remains a significant component of everyday life, therefore the site of the INPP with facilities (i.e. canteen) might become a place to encounter „exotic“ soviet interior, food and atmosphere which could attract the tourists.

Visaginas community and tourists would be interested in trying more innovative touristic routes, which might be commercialized, as 3D simulations while walking in the site of the INPP, or computer games, other simulations to effect a sense of adventure and feeling of danger, even if the INPP strategic objective is to insert and spread safety and security message. 


\section{Public Establishments as the INPP region Business and Tourism Information Centre and others}

Public establishments in Visaginas provide all tourist information: different kind of routes, places of interest, information on events, accommodation, catering. These organizations are non-profit bodies which are established in order to contribute to the development of the region, help small and medium-sized businesses. These centres might contribute to the development of different tourism strategies in the region by helping enterprises to develop different products for commercialization.

\section{Entrepreneurs and SME's}

This group of stakeholders should become the most interested in developing commercialised products and services for tourists in the region. Entrepreneurs will be able to set up catering, accommodation services. We see this group of stakeholders active in commodification of „socialist past“ based on ambivalent ideological place identity strategies of soviet heritage tourism (it was the case of Grūtas Park in Druskininkai - an exposition of Soviet ideological relics). However, as shown by statistics, over the last 5 years the number of active business enterprises in the Visaginas municipality almost has not changed and is about 470, there is a tendency to slight decreases in their number of SME's, from 301 companies in 2013 to 293 companies in 2016. The newly registered number of small and medium-sized enterprises fell to 15 in 2016. This shows that business as a sector is quite weak in the region. People are reluctant to set up their own business on the financial risk or ignorance from where to start and what to pursue.

\section{Artists}

Visaginas community representatives display different attitudes on commodification of the past through heritage tourism. Quite a new trend emerges - Visaginas becomes 'a centre of gravity' for artists and their creative projects (for example, singer from Visaginas Alina Orlova, project "Babocka” by British photo artists Laurie Griffiths and Jonty Tacon, photo journalist Artūras Morozovas, documentary theatre performance 'Žalia pievelè'/ 'Green Meadow'). These artists and performances present Visaginas town and people with their identities and destinies related to closure of the INPP. As R. Baločkaite (2010) states, contradiction of two contesting discourses has been revealed - on the one hand, public denial and forgetting of the Soviet past in official and institutional discourse; on the other hand, private remembrance and nostalgia in everyday life. Meanwhile the artists is a group which expresses an emancipation from the dominant discourses by various forms of artistic and symbolic expression, as their massage is constructed through symbols, metaphors and visual forms. Artists using a variety of artistic forms and genres (photography, painting, theatre performances, etc.) create alternative discourses which differ significantly from 
discourses produced by authorities. For instance, British photo artists Laurie Griffiths and Jonty Tacon in their art project „Babocka“2 develop a narrative on post-industrial landscape which embraces elements of environmental ecological discourse and has some connotations with post-apocalyptic vision and reference to the site of Chernobyl. Similar ideas and discourses are exposed in the documentary theatre performance ,Žalia pievelè“, which presents not only place identity of Visaginas and the INPP but refers to global and European nuclear industry situation, discussing ecological consequences of nuclear industry after hundreds and thousands of years. Besides other representations, Visaginas is portrayed as a town on 3 nuclear-waste repositories -,tombs'. The play exposes associative connection of Visaginas and the INPP with Chernobyl. Thus, such depiction and presentation of post-apocalyptic and post-industrial discourses open the door to the ,dark tourism 'on the one hand, on the other hand opens a new opportunity for education, critical pedagogy, to deal with envinronmental concerns drawing attention to postindustrial landscapes and social consequences of monoindustrial cities.

\section{Scholars/ researchers}

There are numerous researches done while investigating Visaginas phenomenon and providing various data and making intellectual insights on the town and the region. Researchers investigated topics on demographic profile, risk communication, nuclear energy efficiency and security, place identity in the postsocialism era, postindustrial landscape, multiculturalism and multilingual studies. Such problematic topics as construction of urban identities were discussed in scientific literature in Lithuania and abroad. Scholars reveal multilateral and ambiguous identity of Visaginas. These stakeholders express emancipation from dominant local discourses on national and place identity produced by local and national authorities. Scientific articles and monographs contribute to understanding of specificity and uniqueness of Visaginas (multiethnic profile, soviet heritage and strategies of post-soviet identities formation). All this input could contribute to development of educational, nuclear and cultural tourism in the region by applying strategies of self-exoticization and commodification.

Evaluation of interests, expectations and perspectives of these stakeholders allows to arrange 'negotiations' among them and find effective communication means to agree on new ideas on the route and create innovative strategies of representation of place identity in newly emerging nuclear tourism.

\footnotetext{
${ }^{2}$ More information on the project: http://www.babochka.co.uk/
} 
Mažeikienè \& Gerulaitienè, 2018. Commodification of Cultural Identities and/or Empowerment of Local Communities: Developing a Route of Nuclear Tourism

\section{Conclusions}

Referring to scientific literature in the field and analysis of stakeholders in Visaginas, certain commodification strategies could be suggested for the development of nuclear and cultural tourism in Visaginas: transformation of existing Information Centre at the INPP into contemporary Science Center, selfexoticization of the town and tourism workers as the Other. The self-exoticization could be realized by representing the INPP and Visaginas as distinctive and 'exotic' object of atomic industry site and atomic town, by promoting representations of soviet identity and sticking into a newly emerging trend of socialist heritage tourism. Multicultural, multiethnic and multilingual profile of the town could become an important resource and asset of cultural tourism. At the same time this multicultural profile could be associated directly with narratives and storylines of socialist heritage tourism. These main strategies could be complemented by images of green and comfortable city with beautiful nature. In the process of developing nuclear tourist route in Visaginas and the INPP region the scholars and local stakeholders recognize inevitability of (self-) commodification which becomes constituent element of tourism as a “commercialized hospitality'. Empowering strategies of stakeholders in the process of (self-) commodification would imply learning to construct different "commodified personas" (Bunten, 2008) by designing different routes, recognizing and identifying different tourist groups, by representing local and place identities in relation to this variety of tourists. At the same time, one more strategy of (self) commodification should be elaborated - resistance to being objectified according to stereotypes. The widespread stereotype of Visaginas as a soviet city could be challenged by strengthening new layers of identity of the town when Visaginas could be represented as a place of residence of artists and their creative projects, the town with energetic, ambitious, intercultural and openminded youth (the second and the third generation of inhabitants).

The research revealed the value of collaborative and empowering approach for the development of nuclear tourism route while involving local and national stakeholders, negotiating and mediating ways and strategies of local identity building within the framework of more democratic politics of identity and memory. Involvement of the local community creates a bond through mutual understanding and trust.

The research delineates that different groups of stakeholders have different expectations and interests in the development of cultural and nuclear tourism in Visaginas. The official and institutional discourse is reluctant to display identity of the town referring to the socialist past. Meanwhile scholars and artists create alternative discourses which refer to ideas and images of postindustrial landscapes 
and post-apocalyptic imaginary, to socialist and soviet identity of the town. Current art projects on Visaginas demonstrate transforming power of the artistic expression to present alternative discourses and negotiate the process of constructing place identity.

\section{Acknowledgements}

This article presents findings of the research project 'The Didactical Technology for the Development of Nuclear Educational Tourism in the Ignalina Nuclear Power Plant (INPP) Region (EDUATOM)'.

This research was funded by a grant (No. 01.2.2-LMT-K-718-01-0084/232) from the Research Council of Lithuania.

\section{References}

Baločkaitè, R. (2010). Post-Soviet Transitions of the Planned Socialist Towns: Visaginas, Lithuania. Studies of Transition States and Societies 2 (2), 63 - 81.

Baločkaite, R. (2012). 'Coping with Unwanted Past in Planned Socialist Towns: Visaginas, Tychy, and Nova Huta. Slovo 24 (1), 41 - 57.

Beetlestone, J. G., Johnson, C. H., Quin, M., \& White, H. (1998). The Science Center Movement: contexts, practice, next challenges. Public Understanding of Science, 7, 5-26.

Bramwell, B., \& Lane, B. (1999). Collaboration and Partnerships for Sustainable Tourism. Journal of Culture or Selling Out Sustainable Tourism 7, 179-181

Bunten, A. C. (2008). Sharing? Developing the Commodified Persona in the Heritage Industry. American Ethnologist, Vol. 35, No. 3 (Aug., 2008), 380-395.

Cassel, S. H., \& Maureira, T. M. (2017). Performing identity and culture in Indigenous tourism - a study of Indigenous communities in Québec, Canada. Journal of Tourism and Cultural Change, 15:1, 1-14, DOI: 10.1080/14766825.2015.1125910

Galı'-Espelt, N. (2012). Identifying cultural tourism: a theoretical methodological proposal. Journal of Heritage Tourism, Vol. 7, No. 1, February 2012, 45-58.

Freimane, I (2014). Dwelling in Visaginas: The Phenomenology of Post-Socialist Town. Master's Thesis. University of Glasgow and University of Tartu.

Jackson, L. (2006). Ameliorating the negative impacts of tourism: a Caribbean perspective. International Journal of Contemporary Hospitality Management, 18, 574-582.

Young, C., \& Kaczmarek, S. (2008). The Socialist Past and Postsocialist Urban Identity in Central and Eastern Europe. The Case of Łódź. Poland European Urban and Regional Studies. 15 (1), 53-70.

Murtagh, B., Boland, P., \& Shirlow, P. (2017). Contested heritages and cultural tourism. International Journal of Heritage Studies, 23:6, 506-520, DOI: 10.1080/13527258.2017.1287118

Nyaupane, G. P., Morais, D. B., \& Dowler, L (2006). The role of community involvement and number/type of visitors on tourism impacts: A controlled comparison of Annapurna, Nepal and Northwest Yunann, Nepal. Tourism Management, 27 (6), 1373-1385.

Stronza, A. (2008). Through a new mirror: Reflections on tourism and identity in Amazon. Human Organization, 67 (3), 244-257. 
Mažeikienè \& Gerulaitienè, 2018. Commodification of Cultural Identities and/or Empowerment of Local Communities: Developing a Route of Nuclear Tourism

Tukamushaba, E. K., \& Okech, R. N. (2011). Tourism training and education, community empowerment and participation in tourism planning and development: A case of Uganda. Journal of Tourism, 12 (1), 79-102. 